\title{
Jelena Mihaljević Diigunović DO YOUNG LEARNERS KNOW HOW TO LEARN A FOREIGN LANGUAGE?
}

7 here has not been much research to date on language learning strategies used are considered better able to report on learning strategies than younger learners. Most of the methods (e.g., interviews, questionnaires, think-aloud protocols) used to investigate strategies are meant to be used with subjects at a cognitive level above that of young children.

The studies that have been carried out with young language learners mostly include second language learners, that is, children who are learning a non-native language in the country where that particular language is spoken as the native language.

Thus, Wong-Fillmore $(1976,1979)$ reports on her nine-month study of Mexican children (aged between 5;7 to 7;3 years) learning English in a Californian school. In her study she made use of the ethnographic and observational methods. Having recorded five such children's interactions with native American children during playtime, she found considerable variation in the proficiency they reached by the end of the nine months. In an attempt to account for the differences, Wong-Fillmore analysed the strategies the children used in their language learning. Her analysis showed that in their interactions the children used three social strategies (1- Join a group and act as if you understand what's going on, even if you don't; 2 - Give the impression, with a few well-chosen words, that you speak the language; 3- Count on your friends for help) and five cognitive strategies ( 1 - Assume what people are saying is relevant to the situation at hand; 2 - Get some expressions you understand, and start talking; 3 - Look for recurring parts in the formulas you know; 4 - Make the most of what you've got; 5 - Work on the big things first, save the details for later). Wong-Fillmore considers the social strategies to be more important since the children were not aiming at mastering the English language but were interested in establishing social relationships with their native American playmates.

Nikolov (1999) reports on the cognitive strategies used by Hungarian young learners of English as a foreign language (EFL). She claims that repetition is a cognitive strategy that changes with age: in her experience, children stop relying on this strategy around the age of 9 or 10 . The mother-tongue strategy that she noticed her young learners used extensively in an attempt to master English spelling was found to be very helpful. Commenting is a cognitive strategy that Nikolov defines as a combination of guessing intelligently on the basis of clues and translating. She believes that this particular strategy is extremely important in child foreign language learning because 
“a) children guess meanings by relying on their background knowledge of the world, and their mother tongue; $b$ ) it provides all children in the classroom with comprehensible input; $\mathrm{c}$ ) it allows the teacher to build scaffolding on feedback; d) gives children the feeling of success; e) it provides learners with a useful communication strategy of guessing intelligently from linguistic and other clues" (Nikolov 1999:230). As with repetition, the use of this strategy changes with age: as the children's proficiency level increases, they rely on it less.

Using a questionnaire comprising some Strategy Inventory for Language Learning (SILL) (Oxford, 1990) items as well as a number of items designed by O'Malley and Chamot (1995), Julkunen (1999) studied the learning strategies of 12-year-old Finnish learners of English, Swedish, German, French and Russian as the second foreign language. His findings showed the subjects reporting a more frequent use of metacognitive and social strategies than of cognitive strategies. They also used different cognitive strategies with different languages. In contrast to the male subjects, the female subjects were found to be using more metacognitive strategies that aimed at selfmanagement and self-monitoring. Another interesting finding of this Finnish study is that learners of English as the second foreign language reported a more frequent use of almost all strategies than the learners of any of the other foreign languages included. Julkunen attributes this to their having started with a 'difficult language' (Finnish learners consider German, French, Russian and Swedish more difficult than English).

Szulc-Kurpaska (1999) analysed the strategies used by 10-year-old Polish EFL learners while retelling the Little Red Riding Hood story. She found that her subjects made use of formulaic chunks, incorporation, language switch, simplification by omission and overgeneralization. Contrary to popular belief and findings in some other studies, the male subjects generally performed better on the storytelling task than female subjects.

In Croatia researchers are only beginning to study language learning strategies used by young learners. The study to be described focused on young EFL learners' awareness of learning strategies.

\section{Aim}

The aim of this study was to establish which strategies in vocabulary learning the young subjects were aware of. We were also interested in seeing whether there would be any variation in the reported strategies as a function of age, sex and achievement level. 


\section{Sample}

A sample of 23 Croatian young EFL learners took part in the study. Their age ranged from six to nine years. The youngest subject was attending a nursery school, the oldest grade 3 of primary school. The age profile of the sample is presented in Table 1.

Table 1: Age profile of the sample

\begin{tabular}{|l|l|l|l|l|}
\hline Age & 6 & 7 & 8 & 9 \\
\hline No. of subjects & 1 & 6 & 11 & 5 \\
\hline
\end{tabular}

There were four boys and 19 girls in the sample. In terms of the course levels they were attending, 11 subjects belonged to Level 1, seven were attending Level 2 and five were from the Level 3 group. Fourteen subjects were considered by their teacher to be good learners and nine were assessed as poor learners.

\section{Instrument and procedure}

Since the subjects were young children, data was elicited by means of the projection method. They were questioned on how they would teach their doll or Dalmatian dog the following English words: apple, kite, yellow, present, goat, cupboard, bird, island, dangerous and the difference in the pronunciation of fifteen and fifty. One learner offered an unsolicited explanation for teaching the word $X$-ray. Not all the subjects were asked about all of the words (see Table 2 for details). Some subjects were also asked about how they learned English words themselves. The subjects were interviewed individually; most were interviewed in a separate room, but some interviews were carried out in class while the other learners were engaged in the regular learning tasks. This was due to the objective circumstances in which the teaching of English was carried out. Some children were also asked more questions than others in order for them to produce sufficient data on strategies.

All the interviews, carried out in Croatian - the subjects' mother tongue, were recorded and later transcribed. 
Table 2: The number of subjects and strategies reported

\begin{tabular}{|l|l|l|l|}
\hline & No. of subjects & No. of strategies & Average no. of strategies per subject \\
\hline Apple & 23 & 49 & 2.1 \\
\hline Kite & 23 & 37 & 1.6 \\
\hline Yellow & 23 & 43 & 1.8 \\
\hline Present & 6 & 10 & 1.6 \\
\hline Goat & 4 & 6 & 1.5 \\
\hline Cupboard & 4 & 7 & 1.7 \\
\hline Bird & 2 & 7 & 3.5 \\
\hline Island & 4 & 3 & 0.7 \\
\hline Dangerous & 1 & 3 & 3 \\
\hline Fifteen/fifty & 5 & 6 & 1.2 \\
\hline X-ray & 1 & 1 & 1 \\
\hline Own learning & 15 & 31 & 2.1 \\
\hline & & \multicolumn{2}{|l|}{} \\
\hline
\end{tabular}

\section{Results and discussion}

The size and composition of the sample in this study limit the extent to which the results could be generalised. However, the findings of this investigation can be taken as indications of possible trends in language learning strategy use by young learners.

The transcribed interviews offer a wealth of data on young learners' views of how to learn English vocabulary.

It is interesting to note the differences between the ways the young subjects suggested for teaching their favourite characters (a doll, a Dalmatian dog) and the strategies they reported they used in their own learning. It is probably logical to guess that their suggestions reflect the ways they would like to be taught.

Ivona -7 years, female, good learner

Interviewer: (...) What else would you tell her (=the doll) to do, what else could help her to learn that word (=apple)?

Ivona: She should take an apple and stare at it till she remembers the word.

(...)

Interviewer: What did you do to remember a new word?

Ivona: ... Drew.

Interviewer: Did drawing help you to remember the new word?

Ivona: Yes.

Some subjects suggested the same approach to teaching others as they reported using in their own learning, indicating perhaps that they liked the way they were being taught or that they thought it was the only way to learn. 
Ivana -6 years, female, good learner

Interviewer: What could help her to remember that word?

Ivana: Er... she should read... and should learn how to write and... er...

(...)

Interviewer: And what helped you to remember how to say 'zmaj' [kite] in English?

Ivana: I studied.

Interviewer: How?

Ivana: I was reading.

Interviewer: And what else?

Ivana: And... er... learned how to write... er...

Many young learners seemed to believe in vocabulary acquisition by some sort of interaction with or manipulation of the referent. This either meant doing something with the object:

Martina -8 years, female, good learner

Interviewer: And what would you tell your doll to do to remember that 'zmaj' is 'kite'?

Martina: Well... er... to buy one and play with it, or to buy a T-shirt with a kite on...

or implicated its function:

Martina -8 years, female, good learner

Interviewer: And the word 'present', how would you help the doll to remember this word? What would you tell her to do?

Martina: When her birthday comes she should... er... remember that 'dar' is 'present' and...

Sometimes just looking at the object was considered helpful:

Ivona - 7 years, female, good learner

Interviewer: What else could help her to learn that word (=apple)?

Ivona: She should take an apple and stare at it till she remembers the word.

In some interviews there is evidence of the young subjects' language awareness. This is particularly obvious with those learners who insisted that the learner should, first of all, learn how to write and spell in English:

Jelena -8 years, female, good learner

Interviewer: Imagine this Dalmatian dog wants to learn English. What would you tell him to do to remember that 'jabuka' is 'apple'?

(...)

Jelena: (...) Well, I'd teach him the letters, how they are written and pronounced, I'd teach him the Croatian and English alphabets. 
Some young learners suggested that English words should be compared to their Croatian translation equivalents:

Jelena -8 years, female, good learner

Interviewer: How would you help our Dalmatian dog to remember that 'žuta' is 'yellow' and not, say, 'green'? What would you tell him to do?

Jelena: (...) and then I'd tell him that 'yellow' is 'žuta' because we call it 'the yellow colour'...er...(smiles) don't exactly know why though, that 'yellow' is 'zuta' because we say 'zuta' and they say 'yellow'.

This young learner apparently believes in the contrastive approach to foreign language learning.

One successful 8-year-old female subject suggested explicitly that her Dalmatian dog should make use of the positive transfer of the mother tongue:

Katarina -8 years, female, good learner

Interviewer: (...) What would you tell him to do to remember that 'zmaj' is 'kite'?

Katarina: Compare it to the word 'kaj' [interrogatiave pronoun in kajkavian dialect], to remember 'kaj', and then to add ' $t$ '.

Some learners insisted on using transcription instead of the ordinary spelling of words:

Stela - 7 years, female, good learner

Interviewer: What would you tell your doll, what should she do to remember that 'jabuka' is 'apple'?

Stela: To.. er.. to draw an apple... I'd draw her an apple and she should write under the drawing... but not... not the way it is spelt but the way it is pronounced.

The subjects exhibited an awareness of the language learning process too. This is seen from the metacognitive strategies they were mentioning in the interview. Thus, one young learner believed that mastering some basic skills in L1 should precede foreign language learning:

Tomislav -8 years, male, good learner

Interviewer: What would you tell the Dalmatian dog to do to remember that 'jabuka' is 'apple'?

Tomislav: He should learn how to read and write first and only then start learning English...

Many learners insisted on learning by repetition. This implied reading the word many times, writing it down or saying it many times:

Petra - 9 years, female, poor learner

Interviewer: And what would help her (=the doll) to remember that word (=kite)? 
Petra: I'd tell her to read it many times till she remembers it...

Željka - 8 years, female, poor learner

Interviewer: What would you tell your doll to do to remember that 'jabuka' is 'apple'?

Željka: ...Er... to write it in the notebook many times.

Stjepan -7 years, male, poor learner

Interviewer: And what would you suggest he (=the Dalmatian) should do to remember that 'poklon' is 'present'?

Stjepan: To non-stop repeat 'present', 'present' and to learn it by heart.

Learning by imitation was valued as well:

Stjepan -7 years, male, poor learner

Interviewer: What would you recommend the Dalmatian to do to remember that 'jabuka' is 'apple'?

Stjepan: To learn English.

Interviewer: And how?

Stjepan: To repeat after someone who knows English ... someone who knows English should tell him (the word) and he should repeat.

A 7-year-old learner seemed aware of the fact that it takes time to learn something:

Dorotea -7 years, female, good learner

Interviewer: What would you tell your doll to do to remember that 'zmaj' is 'kite'?

Dorotea: (...) to study because she can't remember it all in one day.

Several subjects referred to how learning should be organised physically.

Marija - 7 years, female, good learner

Interviewer: And if the doll didn't know how to write yet, what would you tell her to do?

Marija: Well... er... she should sit at a table and repeat the word all the time.

An 8-year-old boy insisted that his Dalmatian dog should be physically and psychologically ready for learning English.

Tomislav -8 years, male, good learner

Interviewer: And what would you tell him (=the Dalmatian dog) to do at home, when he is alone?

Tomislav: He should play a little and when I get home he would study.

Interviewer: And if he wanted to study by himself, what would you tell him to do?

Interviewer: I'd tell him to eat first and do all the other things and then go and study. 
The young subjects seemed to be aware of the effect of reinforcement by widening their knowledge about the referent.

Valentina - 7 years, female, good learner

Interviewer: What would you tell the Dalmatian to do to remember that 'zmaj' is 'kite' in English?

Valentina: To read stuff about kites.

It is interesting to note that a few learners could not remember how they themselves had learned English words. This may be ascribed to shyness but also to a lack of awareness of the learning process.

It seems that young learners can be quite aware of the teaching process as well. Here they reiterated the teaching strategies they were exposed to in school. One learner had a clear idea about the use of the mother tongue in teaching English:

Tomislav -8 years, male, good learner

Interviewer: What would you tell him to do to remember how to say 'ormar' [wardrobe] in English?

Tomislav: ... In English... I'd tell him in English. If he couldn't understand it, then I'd say it in Croatian (...)

Katarina -8 years, female, good learner

Interviewer: And what helped you to remember that 'žuta' is 'yellow'?

Katarina: We had it in the test... I'd give him (=the Dalmatian dog) the word in a little test too ... er... I'd write the names of some colours... er... and among them 'yellow'... er... and... er... then... er... he'd have to circle... er... that... er... the correct spelling of yellow.

This extract shows how easily what was done to the young learner is carried over to teaching the Dalmatian.

In order to teach the English word goat one young subject suggested using a cartoon about a goat:

Vlatka -8 years, female, good learner

Interviewer: (...) What would you tell the Dalmatian to do to remember that word (=goat)?

Vlatka: (...) and then I'd have him watch a cartoon where the main character would be a goat.

Another learner suggested using a song where a particular word would be repeated many times. The young learners seemed to be aware of the necessity to be exposed to a lot of input, or to intensive input, in order to learn the language material.

Awareness of the teaching strategies they were exposed to is especially visible in the children's frequent inclusion of testing as part of the process. The ways they suggested 
this should be done probably reflect what they had experienced themselves in class or at home:

Jelena -8 years, female, good learner

Interviewer: Well, and what would you tell the Dalmatian to do to remember that word (=present). It's a hard word for him to remember.

Jelena: Present... well... er... (smiles) I'd draw him a present as a gift, and then I'd write the word 'present' under it and then I'd tell him. ... I'd... first I'd ask him how all these letters are said in English and then he would put the word together. Next time I'd give him a test, I wouldn't write the word 'present' but he'd have to put the word together from... jumbled letters, for example ' $r$ ', 'e', 's' and so on...

During the analysis of the transcribed interviews we did not apply any of the already established categorisations of strategies but opted for a data-driven classification. Thus, the total of 209 strategies identified were grouped into seven different groups of strategies. These are presented in Table 3 . The TPR group comprises strategies that involve the learner's physical interaction with what the word means: for example, eating an apple, buying a kite, looking at the sun and the like. The formal learning strategies refer to the typical classroom learning activities such as writing, reading and writing, drawing and writing, drawing and cutting out, etc. The academic group includes the learner's suggestions that the doll/Dalmatian dog should learn the English alphabet first, should study books, go to school regularly and the like. Memory strategies refer to repeating words, or reading or copying them many times. Social strategies include learning or revising vocabulary with someone, often for testing purposes. Metacognitive strategies imply the subject's wish to organise learning (e.g., the Dalmatian dog should eat and rest first and then study, or the doll should sit at the table and reapeat) or to evaluate knowledge by means of tests. The media group of strategies refer to learning by watching cartoons and educational programmes focusing on the English language (e.g., Gogo Loves English).

As can be seen in Table 2, the largest average number of learning strategies reported per learner concerned the words: bird, dangerous and apple, while the least average number of strategies per learner refers to $X$-ray and island.

The most frequently reported group of strategies our young subjects reported were the formal strategies. For 10 out of 12 learning targets, formal language learning strategies were the single most frequent group or the most frequent one together with TPR strategies. A possible tentative conclusion here may be that young learners pick up the strategies they are exposed to or taught to use. This, then, could lead us to assume that even quite young learners can profit from strategies-based-instruction (SBI) (Cohen, 1998).

Social strategies were the least frequent strategies reported for the largest number of learning targets. This is in accordance with the trends found in strategy use by Croatian learners of EFL in general (Mihaljević Djigunović, 2000). 
Table 3: Reported strategies by learning targets

\begin{tabular}{|l|l|l|l|l|l|l|c|}
\hline & TPR & Formal & $\begin{array}{c}\text { Aca- } \\
\text { demic }\end{array}$ & Memory & Social & $\begin{array}{c}\text { Metacog- } \\
\text { nitive }\end{array}$ & Media \\
\hline Apple & $20.41 \%$ & $26.53 \%$ & $18.37 \%$ & $22.45 \%$ & $4.08 \%$ & $4.08 \%$ & $4.08 \%$ \\
\hline Kite & $16.22 \%$ & $29.73 \%$ & $16.22 \%$ & $24.32 \%$ & $2.70 \%$ & $2.20 \%$ & $8.11 \%$ \\
\hline Yellow & $27.91 \%$ & $27.19 \%$ & $9.30 \%$ & $20.93 \%$ & $2.32 \%$ & $9.30 \%$ & $2.32 \%$ \\
\hline Present & $30.00 \%$ & $40.00 \%$ & $10.00 \%$ & $10.00 \%$ & $0.00 \%$ & $10.00 \%$ & $0.00 \%$ \\
\hline Goat & $33.33 \%$ & $33.33 \%$ & $16.67 \%$ & $0.00 \%$ & $0.00 \%$ & $0.00 \%$ & $16.67 \%$ \\
\hline Cupboard & $14.29 \%$ & $57.14 \%$ & $0.00 \%$ & $0.00 \%$ & $0.00 \%$ & $28.57 \%$ & $0.00 \%$ \\
\hline Bird & $28.57 \%$ & $28.57 \%$ & $28.57 \%$ & $0.00 \%$ & $0.00 \%$ & $0.00 \%$ & $14.29 \%$ \\
\hline Island & $33.33 \%$ & $0.00 \%$ & $0.00 \%$ & $66.67 \%$ & $0.00 \%$ & $0.00 \%$ & $0.00 \%$ \\
\hline Dangerous & $0.00 \%$ & $33.33 \%$ & $33.33 \%$ & $33.33 \%$ & $0.00 \%$ & $0.00 \%$ & $0.00 \%$ \\
\hline Fifteen/fifty & $0.00 \%$ & $66.67 \%$ & $0.00 \%$ & $33.33 \%$ & $0.00 \%$ & $0.00 \%$ & $0.00 \%$ \\
\hline X-ray & $0.00 \%$ & $0.00 \%$ & $100 \%$ & $0.00 \%$ & $0.00 \%$ & $0.00 \%$ & $0.00 \%$ \\
\hline Own learning & $3.22 \%$ & $32.26 \%$ & $0.00 \%$ & $22.58 \%$ & $22.58 \%$ & $3.22 \%$ & $16.13 \%$ \\
\hline
\end{tabular}

Although the number of male and female subjects was highly uneven, we counted up the number of strategies used by each sex in order to see a possible tendency in strategy use that might be checked in later studies. The results are presented in Table 4.

Table 4: Strategies reported by male and female subjects

\begin{tabular}{|l|l|l|}
\hline & Male & Female \\
\hline No. of strategies & 39 & 170 \\
\hline Average per learner & 9.8 & 8.9 \\
\hline
\end{tabular}

As can be seen, there does not seem to be too great a difference in the average number of learning strategies reported by male and female subjects. Contrary to other studies in the field, there seems to be a tendency for male learners to report more strategies.

Age as a possible factor influencing strategy use was looked into as well (Table 5). The use of TPR strategies seemed to decrease with age. Formal learning strategies showed a tendency to increase with age, except for the eight-year-old group, where it was lower and where memory strategies seemed to be very frequently reported. It is interesting that social strategies, not reported by the 6-year-old subject at all, decreased with age as well. Since these strategies involved studying with members of the family, maybe this shows that the child's knowledge of English slowly surpassed that of the 
family members, or that such collaboration was not necessary any more because the young learner could manage on his/her own.

Table 5: Reported strategy use breakdown by age

\begin{tabular}{|c|c|c|c|c|c|c|c|}
\hline & TPR & Formal & Academic & Memory & Social & $\begin{array}{l}\text { Meta- } \\
\text { cognitive }\end{array}$ & Media \\
\hline 6 years & $57.14 \%$ & $14.28 \%$ & $0.00 \%$ & $14.28 \%$ & $0.00 \%$ & $14.28 \%$ & $2.22 \%$ \\
\hline 7 years & $22.58 \%$ & $37.10 \%$ & $12.90 \%$ & $9.68 \%$ & $6.45 \%$ & $3.22 \%$ & $3.22 \%$ \\
\hline 8 years & $17.44 \%$ & $20.93 \%$ & $12.79 \%$ & $23.25 \%$ & $5.81 \%$ & $6.98 \%$ & $10.46 \%$ \\
\hline 9 years & $15.55 \%$ & $33.33 \%$ & $6.66 \%$ & $4.44 \%$ & $4.44 \%$ & $4.44 \%$ & $2.22 \%$ \\
\hline
\end{tabular}

Table 6: Reported strategy use breakdown by achievement

\begin{tabular}{|l|c|c|c|c|c|c|c|}
\hline & TPR & Formal & Academic & Memory & Social & $\begin{array}{c}\text { Meta- } \\
\text { cognitive }\end{array}$ & Media \\
\hline $\begin{array}{l}\text { Good } \\
\text { learner }\end{array}$ & $20.15 \%$ & $26.86 \%$ & $11.19 \%$ & $17.91 \%$ & $5.22 \%$ & $8.95 \%$ & $5.97 \%$ \\
\hline $\begin{array}{l}\text { Poor } \\
\text { learner }\end{array}$ & $11.27 \%$ & $38.03 \%$ & $14.08 \%$ & $23.94 \%$ & $5.63 \%$ & $4.22 \%$ & $1.41 \%$ \\
\hline
\end{tabular}

It is interesting to note (Table 6) that the poor language learners reported using fewer TPR strategies and more formal strategies than the good language learners. The poor language learners reported using memory strategies more often than the good language learners. The good language learners seemed to employ metacognitive strategies more often than the poor language learners. The same is true of the media group of strategies.

As already stressed, the findings of the quantitative analysis of the study are meant to point to possible trends that might be explored in future research that would involve a much larger sample.

\section{Conclusion}

The findings of this study suggest the existence of language learning strategy awareness in young learners. In order to find out about the learning strategies they are aware of, one has to use the appropriate research method to elicit the data. One of the methods that can be effective is the projection method. The strategies that young FL learners use are mostly a reflection of what they themselves have been exposed to. The good aspect of this conclusion is that young learners can be taught how to employ those learning strategies that might lead to successful FL learning. An investigation of young learners' language learning strategies may reflect young learners' language awareness as well as their awareness of the learning and teaching processes. 


\section{References}

Cohen, A.D. (1998). Strategies in learning and using a second language. London and New York: Longman.

Fillmore, C., D. Kempler \& W. Wang (Eds.) (1979). Individual differences in language ability and language behavior. New York: Academic Press.

Julkunen, K. (1999). Learning strategies used by fifth-graders when studying foreign languages. Strani jezici 28(3-4), 240-246.

Mihaljević Djigunović, J. (2000). Language Learning Strategies and Affect. CLCS Occasional Paper No. 59, Trinity College, Dublin.

Nikolov, M. (1999). Strategy use in Hungarian children's classrooms through a story-based syllabus. Strani jezici 28(3-4), 225-233.

O’Malley, J. M. \& Chamot, A-U. (1990). Learning strategies in second language acquisition. Cambridge: Cambridge University Press.

Oxford, R. L. (1990). Language learning strategies: what every teacher should know, New York: Newbury House/Harper and Row.

Szulc-Kurpaska, M. (1999). Little Red Riding Hood - natural speech data analysis in 10-yearolds. Strani jezici 28(3-4), 234-239.

Wong-Fillmore, L. (1976). The second time around: cognitive and social strategies in second language acquisition. Unpublished $\mathrm{PhD}$ dissertation, Stanford University.

Wong Filmore, L. (1979). Individual differences in second language acquisition. In C. J. Fillmore, D. Kempler \& W. S. Y. Wang (Eds.), Individual Differences in Language Ability and Language Behavior (pp. 203-228). New York: Academic Press. 